\title{
Reactance and Public Health Messages: The Unintended Dangers of Anti-tobacco PSAs
}

\author{
Norman C. H. Wong ${ }^{1}$, Kylie J. Harrison ${ }^{2}$, Lindsey A. Harvell ${ }^{3}$ \\ ${ }^{1}$ Department of Communication, University of Oklahoma, USA \\ ${ }^{2}$ Mid-America Christian University, USA \\ ${ }^{3}$ School of Communication Studies, James Madison University, USA \\ Correspondence: Dr. Norman C. H. Wong, Department of Communication, University of Oklahoma, 610 Elm Avenue, \\ Norman, OK 73019, USA
}

Received: June 15, 2015 Accepted: August 28, 2015 Online Published: September 24, 2015

doi:10.11114/smc.v3i2.1022 URL: http://dx.doi.org/10.11114/smc.v3i2.1022

\begin{abstract}
This study examined smokers' reactions to antismoking messages that emphasized either the harms of secondhand smoke or vulnerability to smoking addiction and framed the need for smoking cessation using either gain or loss message frames. One hundred fifty-four college smokers participated in a study that used a 2 x 2 factorial design crossing message type (secondhand smoke appeals, smoking addiction appeals) and message frame (gain, loss) with the addition of a control group. The primary outcomes assessed were participants' intentions to quit smoking and psychological reactance. Secondhand smoke appeals paired with a loss-framed smoking cessation message yielded greater reactance and lower intentions to quit compared to smoking addiction PSAs paired with a gain-framed smoking cessation message. Overall, loss framed smoking cessation messages elicited greater message reactance compared to gain framed smoking cessation messages.
\end{abstract}

Keywords: psychological reactance, message framing, anti-smoking PSAs

\section{Introduction}

There is no shortage of evidence that cigarette smoke is harmful for both smokers and nonsmokers alike. Each year tobacco use is responsible for 20 percent of all deaths in the United States and contributes to an additional 38,000 American deaths from smoking-related diseases such as lung cancer and heart disease due to secondhand smoke exposure (Armour, Woollery, Malarcher Pechacek, \& Husten, 2005; Beaudoin, 2002; NCI, 2008). There is also no shortage of public service announcements (PSAs) designed to persuade smokers to quit or to avoid smoking in the presence of others due to the harms associated with secondhand smoke exposure (for a review, see Beaudoin, 2002; Cohen, Shumate, \& Gold, 2007). Some of the traditional themes used in antismoking messages targeting smokers focus on: (a) describing the negative health consequences associated with smoking to elicit fear in viewers, (b) exposing the deceptive practices of the tobacco companies and portraying them as murderers (e.g., the Truth campaign) to elicit anger in viewers and (c) discussing the danger of secondhand smoke to elicit feelings of guilt in viewers (Beaudoin, 2002; Cohen et al., 2007). While these campaigns hope to elicit fear, anger, and guilt to drive smokers to quit smoking, such ads may also provoke unintended and counterproductive responses from smokers such as reactance.

Although the onset of tobacco use typically occurs during early adolescence, tobacco use among college students is a major public health problem that remains inadequately addressed (SAMHSA, 2010). According to the 2010 National Survey on Drug Use and Health, young adults aged 18 to 25 had the highest rate of tobacco product use (40.8\%) compared to youth aged 12 to $17(10.7 \%)$ and adults aged 26 or older (27.2\%) in the United States (SAMHSA, 2010). Thus, we feel college-aged smokers would make for an appropriate population to examine.

\subsection{Purpose of the Study}

This study investigates smokers' responses to anti-smoking PSAs from the perspective of psychological reactance theory. Specifically, it is an applied test of the theory to determine whether reactance occurs among smokers in response to two common arguments (i.e., secondhand smoke is dangerous to all and smoking is a highly addictive behavior associated with many negative consequences) found in antismoking messages (for a review, see Beaudoin, 2002) 
framed to either highlight the gains for quitting or the losses for failure to quit smoking. A review of psychological reactance theory is presented in the next section.

\section{Psychological Reactance Theory}

The theory of psychological reactance (Brehm, 1966; Brehm \& Brehm, 1981; Brehm, Stires, Stensenig, \& Shaban, 1966) advances that the human freedom to choose between behaviors is essential to their ability to flourish. Because freedom is important, when an individual's freedom is taken or even jeopardized, they become motivated to reestablish those coveted freedoms (Brehm, 1966). It is important to note that within reactance theory freedoms are conceptualized not simply in behavioral terms (i.e., what someone can do, when they can do it, or how they can do it), but also in psychological terms (i.e., the freedom to hold a specific attitude or opinion (Brehm, 1966).

When freedom is taken or threatened the individual becomes motivated to regain this freedom. This heightened motivational state is known as reactance (Brehm, 1966). Because reactance generates negative cognitive and affective responses such as agitation, frustration, and anger, individuals are motivated to restore their freedom (Brehm, 1966; Dillard \& Shen, 2005). Burgoon, et al. (2002) advanced that reactant individuals may restore their freedom by "ignoring the persuasive attempt, derogating the source, and even producing even more of the undesired behaviors as a means of demonstrating choice or restoring attitudinal freedom" (p. 215).

Of particular interest to this investigation is the fact that smokers may experience reactance in response to antismoking PSAs that seem to threaten their freedom to hold positive attitudes toward smoking by highlighting the harm of smoking to non-smokers (i.e., smoking is a bad behavior). Feelings of reactance in turn may motivate smokers to ignore the antismoking message (i.e., not process it), to derogate the message source, or even worse, to strengthen their resolve to continue to smoke as a means of expressing their choice, and restoring their threatened freedom (Burgoon et al., 2002). Brehm (1966) advances that even if there is a legitimate rationale to threaten or take away a freedom, the recipients of the persuasive attempts can still experience reactance. For example, anti-smoking PSAs are all well intended and the damaging consequences of smoking are well documented, but even so, a smoker will likely feel reactant because their freedom to smoke is being challenged.

\subsection{Psychological Reactance and Anti-smoking PSAs}

Burgoon et al. (2002) argue that persuasion researchers need to focus their research attention on what message features produce reactance among message receivers. In response, we argue that the message theme of the anti-smoking ads, paired together with the message frame used to promote smoking cessation may hold the key to the success or failure of the PSAs. In particular, secondhand smoke PSAs likely unleashes psychological reactance (Brehm, 1966, 1972; Dillard \& Shen, 2005; See Burgoon, et al., 2002 for review) within the smoker leading to the ultimate failure of the PSA because they demonize the smoker as a dangerous person responsible for harming the health of others. Not only does secondhand smoke PSAs threaten the individual's freedom to choose to smoke, these messages impose an unwanted image on the smoker, as to suggest that they have no choice but to quit smoking. Conversely, we argue that smoking addiction PSAs may provoke less reactance among smokers because they do not demonize the smoker, but rather portrays the smoker as a victim of smoking addiction who has a choice to become free from addiction by quitting smoking. As the level of psychological reactance increases among smokers in response to antismoking PSAs, it is expected that their intentions to quit smoking will decrease. Taken together, we hypothesized that:

H1: Smokers exposed to secondhand smoke PSAs will report higher levels of message reactance compared to those exposed to smoking addiction PSAs or no PSAs.

H2: Message reactance will mediate the relationship between smokers' exposure to secondhand smoke PSAs and intentions to quit smoking such that exposure to the secondhand smoke PSAs will increase levels of message reactance, which in turn will decrease reported intentions to quit smoking.

\subsection{Psychological Reactance and Message Framing}

Not only will the type of PSA likely influence smokers' level of psychological reactance to antismoking PSAs, we argue that the way smoking cessation messages are framed can also influence the level of reactance experienced by the smoker. In particular, health-related PSA messages can either highlight the benefits (i.e., gains) of adopting the recommended behavior or stress the costs (i.e., losses) associated with failure to comply with the recommended behavior (Meyerowitz \& Chaiken, 1987; Rothman, Bartels, Wlaschin, \& Salovey, 2006; Stephenson \& Witte, 2000). We argue that loss framed recommendations may present a greater perceived threat to an individual's freedom to choose because they give the illusion that smokers have no choice than to quit smoking or face punishment, while gain framed recommendations may present less of a perceived threat to freedom for smokers by suggesting that it is really up to the smoker whether to quit or not, without worries about facing negative consequences by not quitting. Thus, we expect that psychological reactance will be more likely to happen when smokers are exposed to a loss framed (vs. gain framed) 
message urging the smoker to quit. Moreover, we feel that as smokers become more reactant toward a message, the lower their intent will be for quitting smoking as a means of restoring their threatened freedom to choose either to smoke or not smoke.

H3: A loss-framed smoking cessation message will elicit a higher level of message reactance than will either a gain-framed smoking cessation message or no message.

H4: Message reactance will mediate the relationship between exposure to a loss-framed smoking cessation message and intentions to quit smoking such that exposure to a loss-framed smoking cessation message will elicit greater levels of message reactance, which in turn will decrease reported intentions to quit smoking.

Since both message theme and message frame are likely to impact a smokers' level of message reactance toward an antismoking PSA, it would be useful to look for a potential interaction between message theme and message frame on smokers' overall level of message reactance. Given that we expect message reactance to be greater for secondhand smoke PSAs and loss-framed smoking cessation messages, it can be hypothesized that:

H5: Message reactance will be highest when secondhand smoke PSAs are paired with a loss-framed smoking cessation message and lowest when smoking addiction PSAs are paired with a gain-framed smoking cessation message.

Moreover, because message reactance likely negatively impacts intentions to quit smoking, it is expected that:

H6: Reported intentions to quit smoking will be lowest when secondhand smoke PSAs are paired with a loss-framed smoking cessation message and highest when smoking addiction PSAs are paired with a gain-framed smoking cessation message.

\section{Emotional Responses to Antismoking PSAs}

In addition to message reactance and intentions to quit smoking, we also expected that smokers would differ in their emotional responses to messages depending on both message theme and message frame. Specifically, secondhand smoke PSAs are typically designed to elicit feelings of guilt within the smoker for causing harm to loved ones through exposing them to secondhand smoke. These types of PSAs often feature a family member, co-worker, or a stranger dying from lung cancer or another smoking-related disease due to secondhand smoke exposure.

\subsection{Guilt and Antismoking PSAs}

Guilt is defined as an emotion that is aroused when an individual feels bad about a behavior (i.e., perceives that they have committed a transgression against someone) while still being okay with the self (Tangney, Wagner, Hill-Barlow, Marschall, \& Gramzow, 1996). Specifically, research has shown that guilt can be very powerful as an influencing mechanism on health behaviors (Miller, Burgoon, \& Hall, 2007; Tangney et al., 1996; Traeen \& Kyalem, 2007). According to Lazarus (1991), guilt is aroused when an individual is made aware of how their behavior is responsible for causing harm (i.e., transgression) to others. By increasing smokers' awareness of how their smoking behavior puts their friends' lives at risk, the feeling of guilt may be elicited. Feelings of guilt are said to motivate reparatory behaviors to make amends for the act of transgression as people who feel guilty often wish that they had acted differently in the guilt-provoking situation (Dillard \& Peck, 2001; Tangney et al., 1996).

H7: Smokers exposed to a secondhand smoke PSAs will report higher levels of guilt than those shown no PSAs.

H8: Feelings of guilt will mediate the relationship between exposure to secondhand smoke PSAs and intentions to quit smoking such that those exposed to secondhand smoke PSAs will report greater feelings of guilt, which in turn should increase intentions to quit smoking.

\subsection{Fear and Antismoking PSAs}

As for smoking addiction PSAs, they typically depict the smoker being unable to break free from becoming addicted to the nicotine found in cigarettes. Some examples of these messages include showing a smoker unable to resist the urge to smoke even in the freezing cold outside, or still lighting up a cigarette while being on an oxygen tank, or while battling cancer. It is argued that such PSAs likely elicit fear in the smoker about developing a long-term addiction to smoking. Fear is an emotion elicited when individuals are made aware of an imminent physical threat or danger and should motivate protective behaviors on the part of the threatened individual (Witte, 1992, 1994). In their meta-analysis, Witte and Allen (2001) found that fear arousal was a positive predictor of intentions to follow the recommended response aimed at averting the threat. This finding is consistent with other previous studies on fear arousal and message acceptance (e.g., Hale \& Dillard, 1995; Hale, Lemieux, and Mongeau, 1998; Mongeau, 1998)

H9: Smokers exposed to a smoking addiction PSAs will report higher levels of fear about smoking addiction than those shown no PSAs.

H10: Feelings of fear about smoking addiction will mediate relationship between exposure to smoking addiction PSAs 
and intentions to quit smoking such that those shown smoking addiction PSAs will report greater levels of fear about smoking addiction, which in turn should increase intentions to quit smoking.

\section{Method}

\subsection{Participants}

Current regular smokers $(\mathrm{N}=154)$ were recruited from undergraduate communication courses at a large Southern university. Participants ranged in age from 18-26 $(M=20.17, S D=1.66)$ and were offered $\$ 25$ gift cards for their participation in the study. The current sample consisted of 66 males (42.9\%) and 88 females (57.1\%). Approximately 73.4\% of the participants were White, 3.2\% African-American, $10.4 \%$ Asian, 6.5\% Hispanic, 5.8\% American Indian/Alaskan Native, and .6\% marked "other." To ensure that all the participants were current daily smokers, they were asked to respond to three questions asking about their current smoking status: (1) Do you currently smoke cigarettes regularly? (yes/no), (2) Have you smoked over 100 cigarettes in your lifetime? (yes/no), and (3) What is the number of cigarettes that you have smoked in the past 30 days? All of these served as screener questions to determine whether individuals are regular daily smokers. Only those who answered yes to both of the dichotomous questions, and reported smoking more than 60 cigarettes (i.e., average of 2 cigarettes a day) in the past 30 days were allowed to participate in the study. To ensure that participants were not motivated to lie about their smoking status (i.e., a nonsmoker claiming to be a smoker) in order to receive the $\$ 25$ incentive, a concurrent study was done offering the same incentive to non-smokers. Additionally, participants were asked to produce smoking paraphernalia (e.g., lighter, pack of cigarettes) when they picked up their $\$ 25$ gift card.

\subsection{Study Design}

To test the study hypotheses, a 2 (PSA theme: secondhand smoke or smoking addiction) x 2 (smoking cessation message frame: gain or loss) pretest-posttest experiment was conducted. A control condition was added in which participants did not see any antismoking PSAs. The control condition just presented a screen with text describing the prevalence of smoking in the U.S., the different ingredients typically found in cigarettes, and the manufacturing process of producing commercial cigarettes.

The two antismoking message themes were presented via the use of several antismoking PSAs that featured as their key thematic argument that "secondhand smoke poses a significant health threat to significant others as well as strangers and your smoking habit is responsible for causing the harm" or that "cigarettes are highly addictive and the tobacco companies is responsible for keeping you hooked on cigarettes." In addition to the antismoking PSAs, participants were also exposed to a textual message following the PSAs that provided the smoking cessation message frame manipulation highlighting either the benefits of quitting smoking (gain-framed) or the costs of failing to quit smoking (loss- framed) as well as brief efficacy information aimed at helping smokers to quit smoking (i.e., a toll free number to the local state quit line).

\subsection{Procedures}

Participants were first directed to an online link where they read a consent form and indicated acceptance by clicking on the link to get them to the study website. Following consent, participants were randomly assigned to 1 of 5 message conditions: secondhand smoke PSAs paired with a gain-framed smoking cessation message $(n=32)$, secondhand smoke PSAs paired with a loss-framed smoking cessation message $(n=31)$, smoking addiction PSAs paired with a gain-framed smoking cessation message $(n=28)$, smoking addiction PSAs paired with a loss-framed smoking cessation message $(n=33)$, or a control message that discussed the prevalence of smoking in the U.S., the ingredients found in cigarettes, and the manufacturing process of producing cigarettes $(n=30)$.

For those in the treatment conditions, prior to their exposure to the PSAs (secondhand smoke/smoking addiction) and the message frame manipulation, participants were instructed to complete a series of pretest items. Participants were then directed to an online link opening up a new window where they were asked to watch a series of secondhand smoke PSAs or smoking addiction PSAs. Participants assigned to the control condition did not watch any videos. Next, participants in the treatment conditions read a text message that informed them either of the benefits of quitting smoking (gain-framed) or the costs of failing to quit smoking (loss-framed). Lastly, they were provided with a specific smoking cessation resource to help them with smoking cessation (i.e., toll free number of the state tobacco quit line). Participants in the control condition were only shown the control message described earlier. All participants then responded to the set of outcome items. They were then debriefed and asked to provide contact information (i.e., name, e-mail address, phone number) so that they could be notified about when and where to pick up their $\$ 25$ gift cards.

\subsection{Stimulus PSAs and Message Frame Manipulations}

In selecting the secondhand smoke and smoking addiction PSAs for this study, a variety of PSAs found online that were aired both nationally and internationally were examined. For the secondhand smoke PSAs condition, smokers watched a 
total of 2 ads that were randomly ordered, one was set in a restaurant scene where nonsmoking diners were shown exhaling smoke during their conversations as a nearby smoker lights up to smoke a cigarette. The voiceover cites statistics to show about how many nonsmokers die each year from smoking-related diseases such as emphysema, heart disease, and lung cancer due to secondhand smoke and that there is no safe level of secondhand smoke exposure for nonsmokers. The other PSA used was set in a bar scene where the female bartender is shown talking to a guy before disappearing in a cloud of smoke. The voiceover provides statistics about how many involuntary smokers die each year from secondhand smoke and ends by asking the question, "Are you okay with that?" For the smoking addiction PSA condition, smokers were shown 2 ads in random order that depicted smokers being chained to their cigarettes. In one ad, we see a young college-aged female taking a puff and trying to throw the cigarette away only to have it fly back into her mouth. In the other ad, it shows an older woman smoking a cigarette despite having a hole through her throat and she talks about how she started smoking when she was 17 and is now unable to give up her smoking habit because of nicotine addiction.

As for the message frame manipulations, the gain frame messages emphasized the benefits of quitting whereas the loss frame message highlighted the costs of failing to quit smoking. For example, the gain-framed smoking cessation message in the secondhand smoke PSAs condition read: By making the effort to try to quit today, you help reduce your close friends' risks for heart disease, stroke, and cancer by protecting them from the dangers of secondhand smoke. In contrast, here's an example of a loss-framed smoking cessation message in the secondhand smoke PSAs condition: By failing to make the effort to try and quit today, you help contribute to your close friends' risk for developing heart disease, stroke, and cancer by continuing to expose them to the dangers of secondhand smoke. Great care was taken to ensure that the smoking cessation messages were equivalent except in the way it was framed. The length of the messages and other content not directly related to the message frame were kept constant.

\subsection{Measures}

For a majority of the dependent variables examined in the study, there was a pretest measure of that same variable. The following is a list of the variables of interest for this study where a pretest measure was included: (a) intention to quit smoking, (b) feelings of anger toward the tobacco companies, and (c) feelings of guilt. For the items measuring anger and guilt, these were modified items of the emotion measures used by Dillard and Peck (2001). Intention to quit smoking was measured using a scale previously developed by Wong and Cappella (2009).

\subsubsection{Manipulation Check Measures}

To ensure that participants who received the message frame manipulations perceived the message frame as intended, they were asked to make a judgment about the emphasis of the smoking cessation message on the following word pairs: (a) costs/benefits, (b) loss/gain, and (c) negative/positive outcomes along a 7-point scale. These induction check items were taken from Shen and Dillard (2009) and yielded a good reliability of $\alpha=.83$. It is worth noting that those in the control group were not asked to respond to these items as they did not receive a gain-framed or loss-framed smoking cessation message.

\subsubsection{Pretest Measures}

\subsubsection{Intention to Quit Smoking}

Participants' intention to quit smoking was measured with 6 items on a 5-point scale. The items were taken from Wong and Cappella (2009) and specifically asked how likely is it that in the next 3 months they will: (a) quit smoking completely and permanently, (b) reduce the number of cigarettes you smoke in a day, (c) talk to someone (friend, family member, or spouse) about quitting smoking, (d) buy a nicotine replacement product (patch, lozenge) to help you quit smoking, (e) seek counseling/support (calling a quit line) to help you quit smoking, and (f) enroll in a smoking cessation program if one were available to you at minimal cost and easy access. The items were averaged and yielded acceptable reliability $(\alpha=.79)$.

\subsubsection{Fear about Smoking Addiction}

Four items assessed the extent to which participants felt fearful about smoking addiction. These items were modified from a fear subscale developed by Dillard and Peck (2001). Specifically, they asked the degree to which respondents felt: (a) afraid that you will become addicted to smoking, (b) scared that you will develop a smoking dependency, (c) worried that you will become hooked on cigarettes, and (d) anxious about developing a smoking addiction on a 5-point scale from (1) not feeling this way at all to (5) feeling this way very strongly. The items were averaged into an index yielding strong reliability $(\alpha=.92)$.

\subsubsection{Guilt about Secondhand Smoke}

Three items assessed the degree to which participants felt guilty about secondhand smoke. These items were modified 
versions of Dillard and Peck's (2001) guilt subscale. Specifically, they were asked the extent to which they: (a) felt regret for exposing others to their secondhand smoke, (b) felt guilty about their bad behavior of exposing others to their secondhand smoke, and (c) felt ashamed about exposing others to their secondhand smoke on a 5-point scale from (1) not feeling this way at all to (5) feeling this way very strongly. The items were averaged into an index and yielded good reliability $(\alpha=.80)$.

\subsubsection{Posttest Measures}

The same sets of pretest items used to measure respondents' emotional responses to the PSAs (fear about smoking addiction, guilt about exposing others to secondhand smoke), and intention to quit smoking were used again for the posttest. The only additional posttest measure used was the message reactance measure.

\subsubsection{State Message Reactance}

Participants' level of message reactance was assessed using a variety of measures assessing the different dimensions of reactance, including: (a) perceived threat to freedom (Dillard \& Shen, 2005), (b) level of counterarguing (Silvia, 2006), (c) extent to which individual experienced negative cognitions (Miller et al., 2007), and (d) level of anger experienced toward the message (Dillard \& Shen, 2005; Miller et al., 2007). Specifically, participants were asked to what extent they agreed with different statements meant to tap each of these dimensions.

Three items assessed participants' perceived threat to freedom (e.g., the message tried to make a decision about my smoking behaviors for me, the message tried to manipulate me into quitting smoking, the message tried to control my behavior). These were averaged across to create an index yielding good reliability $(\alpha=.88)$

Three items assessed participants' level of counterarguing (e.g., I criticized the message while I was reading it, I thought of arguments or points that went against the message while I was reading it, I came up with specific responses to the arguments made in the message). These were averaged across to create an index yielding good reliability $(\alpha=.81)$.

Three items assessed participants' level of negative cognitions toward the message (e.g., I felt the message was unreasonable, I felt the message was unfair, I felt the message was exaggerated), and these were averaged into an index with good reliability $(\alpha=.91)$

Lastly, four items tapped at participants' level of anger toward the message (e.g., the message made me feel: irritated, annoyed, angry, infuriated). These items were averaged into an index yielding a good reliability $(\alpha=.89)$. All of the survey items were measured on a 7-point scale with (1) strongly disagree to (7) strongly agree. These items were used to reflect both the cognitive and affective dimensions of reactance that Dillard and Shen (2005) conceptualized in their study. To determine overall level of message reactance, all of the indexes were averaged together yielding a single reactance score for each participant. The higher the score, the greater the level of message reactance.

\section{Results}

\subsection{Descriptive Statistics}

The following is a summary of the means and standard deviations for the posttest measures of the variables of interest in this study: (a) reactance $(M=2.71, S D=.61)$, (b) intention to quit smoking $(M=2.37, S D=.70)$, (c) fear about smoking addiction $(M=2.12, S D=.08)$, (d) anger about nicotine addiction $(M=1.73, S D=.19)$, (e) guilt about exposing others to secondhand smoke $(M=2.06, S D=.31)$, and (f) efficacy about quitting smoking $(M=2.26, S D=.29)$. For all analyses, the pretest scores for the different measures (with the exception of reactance) were controlled for.

\subsection{Manipulation Check}

To check the effectiveness of the message frame manipulation, a t-test was performed comparing those who received the gain-framed recommendation message versus those who received the loss-framed recommendation message on the induction check measure. The higher the score reported on the induction check items, the more the participants felt the message emphasized the benefits of compliance (i.e., agreed that it was a positive frame). The t-test revealed a significant difference between those receiving the gain-framed message $(M=4.78, S D=.44)$ and those who received the loss-framed message $(M=3.16, S D=.46), t(122)=20.00, p<.001$. The message frame manipulation was successful.

\subsection{Test of the Hypotheses}

A series of analyses of covariances (ANCOVAs) were used to test some of the study hypotheses. To test H1, H7, and H9, message theme (secondhand smoke PSAs, smoking addiction PSAs) served as the independent factor. Message frame for the smoking cessation message urging smokers to quit (gain, loss) served as the grouping factor in the ANCOVA to test $\mathrm{H} 3$. All of the meditational hypotheses ( $\mathrm{H} 2, \mathrm{H} 4, \mathrm{H} 8$, and $\mathrm{H} 10)$ were tested using the SPSS MEDIATE Macro (Hayes, 2011). The macro estimates total direct and indirect effects of independent variable on the dependent variable through a proposed mediator variable generating bootstrapped confidence intervals that determine significance 
of the mediation tests (i.e., if the model generated bootstrapped C.I. does not include zero as a value, the mediation is significant). To test $\mathrm{H} 2$ and $\mathrm{H} 4$, message reactance served as the mediator variable, with exposure to secondhand smoke PSAs and loss-framed PSAs serving as the respective independent variables, and intentions to quit smoking as the dependent variable. For $\mathrm{H} 8$ and H10, feelings of guilt about secondhand smoke and fear about smoking addiction were the respective mediator variables, with intention to quit smoking as the dependent measure. Exposure to secondhand smoke PSAs served as the independent variable in testing H8, and exposure to smoking addiction PSAs was the independent factor in testing H10. Across all the analyses, age, sex, and nicotine dependence served as covariates.

\subsubsection{Hypothesis One}

H1 predicted that smokers exposed to secondhand smoke PSAs would report higher levels of reactance than those shown smoking addiction PSAs or shown no PSAs. For reactance, controlling for the covariates, $F(2,142)=8.58$, $p<.001$, partial $\eta^{2}=.11$, the overall model was significant. Inspection of the marginal means show that those exposed to secondhand smoke PSAs reported significantly higher levels of reactance $(M=3.17, S E=.15)$ than those shown the smoking addiction PSAs $(M=2.64, S E=.15)$ and those shown no PSA $(M=2.12, S E=.21)$. Thus, H1 was supported.

\subsubsection{Hypothesis Two}

$\mathrm{H} 2$ predicted that message reactance would mediate the relationship between exposure to secondhand smoke PSAs and intentions to quit smoking. As shown in figure 1, controlling for covariates and pretest intentions to quit smoking, a significant indirect effect was found for message reactance on the relationship between exposure to secondhand smoke PSAs and posttest intentions to quit smoking. The indirect effect of message reactance was significant (effect $=-.094$, $\mathrm{SE}=.05$ ), with a generated bootstrapped confidence interval that excludes zero (lower limit $=-.205$, upper limit $=$ -.018). The direct relationships between the independent, mediator, and dependent variables were for the most part significant. Based on the mediation test, $\mathrm{H} 2$ was supported.

Figure 1. Mediation model of message reactance on the relation between exposure to secondhand smoke PSAs and intentions to quit smoking. Indirect effect of reactance $=-.094(.05), p<.05$, bootstrap confidence interval $(-.205,-.018)$. Standard errors are reported in parentheses. Asterisk indicates $p<.05$.

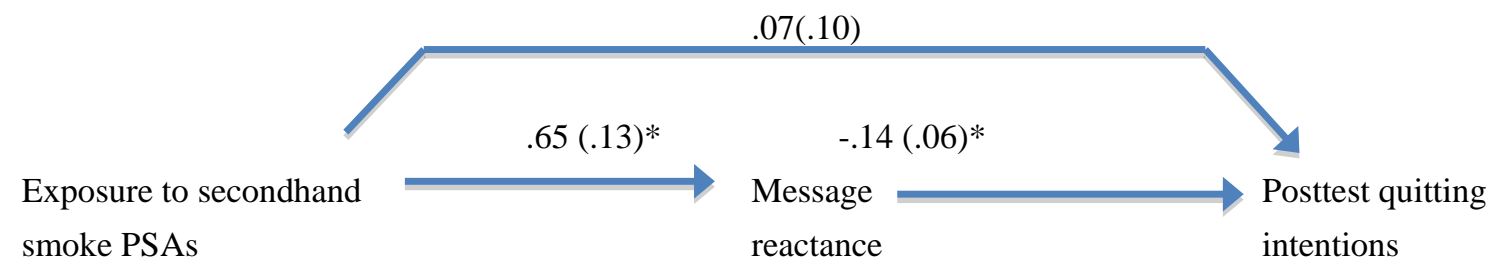

\subsubsection{Hypothesis Three}

H3 predicted that smokers exposed to a loss-framed smoking cessation message would report more message reactance than will those receiving a gain framed smoking cessation message or those receiving no smoking cessation message at all. Controlling for covariates, the overall model was significant, $F(2,142)=13.20, p<.001$, partial $\eta^{2}=.16$. Examination of the marginal means show that smokers receiving the loss framed recommendation message $(M=3.29$, $S E=.14)$ were significantly more reactant toward the message compared to those getting the gain framed recommendation $(M=2.49, S E=.15)$ or those receiving none at all $(M=2.12, S E=.21)$. It is worth noting that the difference in reactance scores between those receiving the gain-framed recommendations to quit smoking versus those receiving no recommendations was not significant. Thus, $\mathrm{H} 3$ was supported.

\subsubsection{Hypothesis Four}

$\mathrm{H} 4$ predicted that message reactance mediates the relationship between exposure to a loss-framed smoking cessation message and intentions to quit smoking. Figure 2 illustrates a significant indirect effect was found for message reactance (effect $=-.075, S E=.04$ ) on the relations between exposure to a loss-framed cessation message and posttest intentions to quit smoking (controlling for covariates and pretest quitting intentions). The generated bootstrap confidence interval excludes zero (lower limit $=-.163$, upper limit $=-.007$ ). Significant direct relationships were found between the independent, mediator, and dependent variables (see Figure 2). Based on the mediation test, H4 was supported.

Figure 2. Mediation model of message reactance on the relation between exposure to loss-framed smoking cessation message and intentions to quit smoking. Indirect effect of reactance $=-.075(.04), p<.05$, bootstrap confidence interval $(-.163,-.007)$. Standard errors are reported in parentheses. Asterisk indicates $p<.05$. 


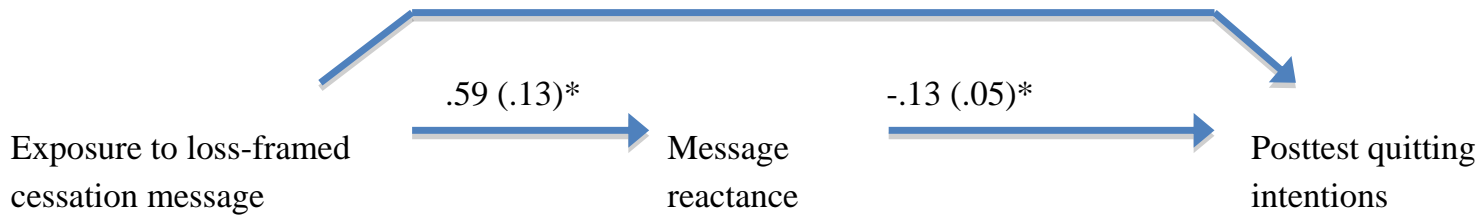

\subsubsection{Hypothesis Five}

H5 predicted an interaction effect between message theme and message frames on smokers' level of message reactance. Specifically, it was anticipated that message reactance ratings would be highest when secondhand smoke PSAs were paired with a loss-framed smoking cessation message, and lowest when smoking addiction PSAs were paired with a gain-framed smoking cessation message. For message reactance, controlling for covariates, the overall model was significant, $F(7,111)=4.76, p<.001$, partial $\eta^{2}=.23$. The interaction term (message theme $\mathrm{x}$ message frame) was a significant factor, $F(1,111)=4.65, p<.05$, partial $\eta^{2}=.04$. Looking at the estimated marginal means, smokers who viewed secondhand smoke PSAs paired with a loss framed cessation message reported the highest level of reactance among all groups $(M=3.82, S E=.21)$ followed by those who viewed smoking addiction PSAs paired with a loss framed cessation message $(M=2.81, S E=.20)$, then smokers who saw secondhand smoke PSAs paired with a gain framed cessation message $(M=2.54, S E=.20)$, and least reactant were smokers shown smoking addiction PSAs paired with a gain framed cessation message ( $M=2.43, S E=.22)$. Thus, $\mathrm{H} 5$ was supported.

\subsubsection{Hypothesis Six}

H6 predicted an interaction effect between message theme and message frame on intentions to quit smoking. It was expected that smokers exposed to secondhand smoke PSAs paired with a loss-framed cessation message report the lowest intentions to quit smoking while those exposed to smoking addiction PSAs paired with a gain-framed cessation message report the highest intentions to quit smoking. Controlling for covariates, including pretest intentions to quit, the overall model was significant, $F(8,139)=5.80, p<.001$, partial $\eta^{2}=.30$. Specifically looking at the interaction term, this was a significant factor, $F(1,139)=4.26, p<.05$, partial $\eta^{2}=.03$. Examining the estimated marginal means, smokers who viewed smoking addiction PSAs with a gain framed cessation message reported the highest intentions to quit ( $M=3.40$, $S E=.15)$, followed by those who viewed secondhand smoke PSAs paired with a gain framed cessation message $(M=2.80$, $S E=.14)$, followed by those who viewed smoking addiction PSAs paired with a loss framed cessation message $(M=2.33$, $S E=.14$ ), and lowest intentions to quit were reported by those who viewed secondhand smoke PSAs paired with a loss framed smoking cessation message $(M=2.31, S E=.15)$. Overall, H6 was supported.

\subsubsection{Hypothesis Seven}

H7 predicted that smokers exposed to secondhand smoke PSAs would report higher levels of guilt than those shown no PSAs. Results show that controlling for covariates, including pretest guilt ratings, those shown secondhand smoke PSAs reported more

posttest guilt $(M=2.98, S E=.12)$ than those shown no PSAs $(M=2.21, S E=.17)$, with the overall model being significant, $F(2,141)=10.73, p<.001$, partial $\eta^{2}=.13$. Of note, those shown secondhand smoke PSAs also reported significantly higher guilt than smokers shown smoking addiction PSAs $(M=2.28, S E=.12)$. Thus, H7 was supported.

\subsubsection{Hypothesis Eight}

H8 predicted that feelings of guilt mediate the relationship between exposure to secondhand smoke PSAs and intentions to quit smoking. No significant indirect effect was found for posttest guilt (effect $=.049, S E=.03$ ), controlling for covariates, pretest guilt ratings, and pretest intentions to quit. The generated bootstrap confidence interval includes zero (lower limit $=-.006$, upper limit $=.119$ ). Results indicated that while exposure to secondhand smoke PSAs did increase feelings of guilt among smokers $(\boldsymbol{\beta}=.425, S E=.11, t=3.88, p<.001)$, posttest ratings of guilt was not significantly related to intentions to quit smoking, $(\boldsymbol{\beta}=.114, S E=.07, t=1.70, p=.09$; see Figure 3$)$. H8 was not supported.

Figure 3. Mediation model of posttest guilt on the relation between exposure to secondhand smoke PSAs and intentions to quit smoking. Indirect effect of posttest guilt $=.049(.03), p=\mathrm{ns}$, bootstrap confidence interval $(-.006, .119)$. Standard errors are reported in parentheses. Asterisk indicates $p<.05$.

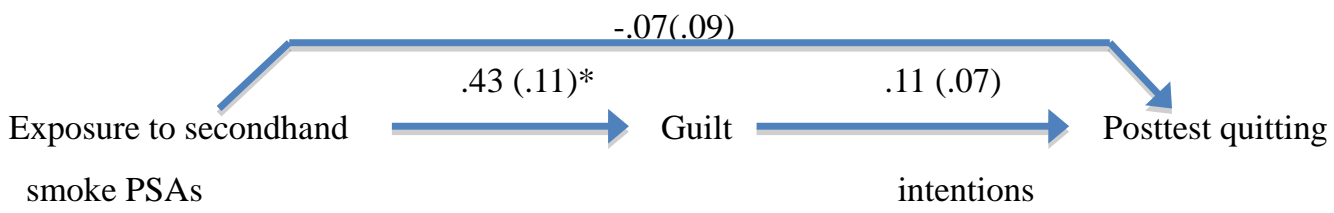




\subsubsection{Hypothesis Nine}

$\mathrm{H} 9$ predicted that smokers exposed to smoking addiction PSAs will report higher levels of fear about smoking addiction than those shown no PSA. Controlling for the covariates, including pretest ratings of fear about smoking addiction, the overall model was significant, $F(1,84)=5.85, p<.05$, partial $\eta^{2}=.07$, with those exposed to the smoking addiction PSAs reporting higher levels of fear $(M=4.34, S E=.25)$ than those shown no PSAs $(M=3.29, S E=.35)$. Thus, H9 was supported.

\subsubsection{Hypothesis Ten}

H10 predicted that fear of addiction mediates the relationship between exposure to smoking addiction PSAs and intentions to quit smoking. Controlling for covariates, pretest fear ratings, and pretest intentions to quit smoking, no significant indirect effect was found for posttest fear of addiction (effect $=-.001, S E=.01$ ). The generated bootstrap confidence interval includes zero (lower limit $=-.028$, upper limit $=.027$ ). While fear about smoking addiction did not mediate the link between exposure to smoking addiction PSAs and intent to quit smoking, a significant direct relationship $(\boldsymbol{\beta}=.389, S E=.09, t=4.21, p<.001)$ was found instead (see Figure 4). Based on the mediation results, H10 was not supported.

Figure 4. Mediation model of posttest fear about smoking addiction on the relation between exposure to smoking addiction PSAs and intentions to quit smoking. Indirect effect of posttest fear $=-.001(.01), p=\mathrm{ns}$, bootstrap confidence interval $(-.028, .027)$. Standard errors are reported in parentheses. Asterisk indicates $p<.05$.

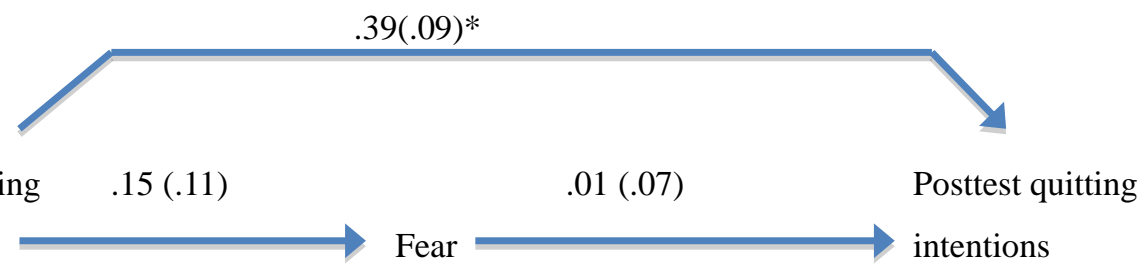

$\begin{array}{llll}\text { Exposure to smoking } .15(.11) \longrightarrow \text { Fear } \longrightarrow & .01(.07) \longrightarrow \text { Posttest quitting } \\ \text { addiction PSAs } \longrightarrow & & \text { intentions }\end{array}$

\section{Discussion}

The main objective of this study was to examine how smokers would react to differently themed antismoking PSA ads (secondhand smoke PSA, smoking addiction PSA) paired with either a gain or loss framed recommendation message urging them to quit smoking. Several interesting findings are worth noting. First, while secondhand smoke PSAs are somewhat effective at motivating smokers to consider quitting, it is important to note that this type of PSA also promotes a high level of reactance among smokers, which may counteract the positive effects the ads may have on promoting smoking cessation. An alternative may be to focus more efforts on using smoking addiction PSAs to get smokers, particularly college smokers, to quit smoking by raising their awareness of their susceptibility to smoking addiction in the long term. Smokers exposed to a smoking addiction ad reported relatively high intentions to quit (compared to controls shown no PSAs) and also low levels of psychological reactance towards the ad. Second, the results clearly show that in offering a recommendation message to urge smokers to quit (i.e., in framing the efficacy message), it is best to use a gain-framed as opposed to a loss-framed format (i.e., emphasizing the benefits to be experienced by the smoker upon quitting rather than the costs of failing to quit). This has implications for how antismoking message campaigners design their efficacy messages to try and motivate smoking cessation. Related to this finding, one of the noteworthy results of this study is that the combination of both a secondhand smoke PSA and a loss-framed recommendation (i.e., efficacy) message elicits the most reactance among smokers and lowest intentions to quit among the different combinations (i.e., message theme $\mathrm{x}$ message frame), whereas a smoking addiction PSA paired with a gain-framed recommendation message elicited the least amount of reactance and the highest intentions to quit among the different combinations. From an applied perspective, this is practical information to have when considering how best to craft antismoking messages.

\subsection{Implications and Directions for Future Research}

Despite finding support for most of the hypotheses, there were some surprises as well. First, while secondhand smoke PSAs elicited more reactance than smoking addiction PSAs, they were also somewhat effective at promoting smoking cessation intention, that is, as long as the efficacy message highlighted the benefits of quitting rather than the costs of not quitting. Interestingly, smokers exposed to the smoking addiction PSA did not report feeling more anger toward the tobacco industry compared to those shown no PSA. One possible explanation might be due to the fact that smokers don't really blame tobacco companies for their lifestyle behavior choice (i.e., they chose to smoke and weren't forced to do so). In the smoking addiction PSAs, no arguments were made to explicitly blame the tobacco companies for causing smoking addiction among smokers. In future studies, it would be interesting to explore whether making an explicit argument against the tobacco industry is an effective tactic to get young smokers to quit, as an expression of 
outrage against tobacco companies. Neither feelings of anger toward the tobacco companies nor fear about smoking addiction were significant predictors of smokers' intention to quit. This is intriguing given that smoking addiction PSAs in general seemed to work better at motivating intentions to quit. Perhaps it has less to do with the message theme and more to do with the framing of the recommendation message that mainly drives smokers' motivations to quit or not quit. Future research could explore further into identifying the specific mechanism through which smoking addiction PSAs influences smokers to consider quitting smoking. One possibility may be that by discussing smoking behavior as an addiction, something that takes control away from an individual, the act of choosing to quit serves as an expression of independence. And it is this feeling of self-liberation that motivates intentions to quit as opposed to driven by emotions such as anger or fear.

\subsection{Concluding Remarks}

In closing, this study attempted to shed some light on how smokers react differently to antismoking PSAs based on the theme of the ads used as part of the "threat" component as well as the way the "efficacy" messages are framed. Both of these elements work interactively to influence smokers' level of psychological reactance toward the message and their intentions to quit smoking. From a practical campaign perspective, the results of this research suggest that antismoking campaigners need to be wary of possible unintended negative effects their messages have on smokers such as provoking reactance, which in turn, may undermine efforts to promote smoking cessation in the long run.

\section{References}

Armour, B. S., Woollery, T., Malarcher, A., Pechacek, T. F., \& Husten, C. (2005). Annual smoking-attributable mortality, years of potential life lost, and productivity losses-United States, 1997-2001. Morbidity and Mortality Weekly Report, 54, 625-628.

Beaudoin, C. E. (2002). Exploring antismoking ads: Appeals, themes, and consequences. Journal of Health Communication, 7, 123-137. http://dx.doi.org/10.1080/10810730290088003

Biener, L., McCallum-Keeler, G., \& Nyman, A. L. (2000). Adults' response to Massachusetts anti-tobacco television advertisements: Impact of viewer and advertisement characteristics. Tobacco Control, 9, 401-407. http://dx.doi.org/10.1136/tc.9.4.401

Brehm, J. W. (1966). A theory of psychological reactance. New York: Academic.

Brehm, J. W. (1972). Responses to loss of freedom: A theory of psychological reactance. Morristown, NJ: General Learning Press.

Brehm, J. W., Stires, L. K., Stensenig, J., \& Shaban, J. (1966). The attractiveness of an eliminated choices alternative. Journal of Experimental Social Psychology, 2, 301-313. http://dx.doi.org/10.1016/0022-1031(66)90086-2.

Brehm, S. S., \& Brehm, J. W. (1981). Psychological Reactance: a theory of freedom and control. New York: Academic Press.

Burgoon, M., Alvaro, E., Grandpre, J., \& Voloudakis, M. (2002). Revisiting the theory of psychological reactance: Communicating threats to attitudinal freedom. In J. P. Dillard \& M. Pfau (Eds.), The persuasion handbook: Developments in theory and practice (pp. 213-232). Thousand Oaks, CA: Sage.

Chapman, S. (2003). Other people's smoke: What's in a name? Tobacco Control, 12, 113-114. http://dx.doi.org/10.1136/tc.12.2.113

Cho, H., \& Boster, F. J. (2008). Effects of gain versus loss frame antidrug ads on adolescents. Journal of Communication, 58, 428-446. http://dx.doi.org/10.1111/j.1460-2466.2008.00393.x

Cho, H., \& Salmon, C. T. (2007). Unintended effects of health communication campaigns. Journal of Communication, 57, 293-317. http://dx.doi.org/10.1111/j.1460-2466.2007.00344.x

Cohen, E. L., Shumate, M. D., \& Gold, A. (2007). Anti-smoking media campaign messages: Theory and practice. Health Communication, 22(2), 91-102. http://dx.doi.org/10.1080/10410230701453884

Dillard , J. P., \& Peck, E. (2001). Persuasion and the structure of affect. Human Communication Research, $27,38-68$. http://dx.doi.org/10.1111/j.1468-2958.2001.tb00775.x

Dillard, J. P., \& Peck, E. (2000). Affect and persuasion: Emotional responses to public service announcements. Communication Research, 27(4), 461-495. http://dx.doi.org/10.1177/009365000027004003

Dillard, J. P., \& Shen, L. (2005). On the nature of reactance and its role in persuasive health communication. Communication Monographs, 72, 144-168. http://dx.doi.org/10.1080/03637750500111815

Farrelly, M. C., Davis, K. C., Haviland, M. L., Messeri, P., \& Healton, C. G. (2005). Evidence of a dose-response 
relationship between "truth" antismoking ads and youth smoking prevalence. American Journal of Public Health, 95(3), 425-431. http://dx.doi.org/10.2105/ajph.2004.049692

Goldman, L. K., \& Glantz, S. A. (1998). Evaluation of antismoking advertising campaigns. Journal of the American Medical Association, 279, 772-777. http://dx.doi.org/10.1001/jama.279.10.772

Hale, J. L., \& Dillard, J. P. (1995). Fear appeals in health promotion campaigns: Too much, too little, or just right? In E. Maibach \& R. L. Parrott (Eds.), Designing health messages: Approaches from communication theory and public health practice (pp. 65-80). Thousand Oaks, CA: Sage.

Hale, J. L., Lemieux, R., Mongeau, P. A. (1995). Cognitive processing of fear-arousing message content. Communication Research, 22, 459-474. http://dx.doi.org/10.1177/009365095022004004

Hayes, A. (2011). MEDIATE SPSS Macro. (Online download). Available from:

http://www.afhayes.com/spss-sas-and-mplus-macros-and-code.html

Hyland, A., Wakefield, M., Higbee, C., Szczypka, G., \& Cummings, K. M. (2006). Anti-tobacco television advertising and indicators of smoking cessation in adults: A cohort study. Health Education Research, 21(3), 348-354. http://dx.doi.org/10.1093/her/cyh068.

Kear, M. E. (2002). Psychosocial determinants of cigarette smoking among college students. Journal of Community Health Nursing, 19, 245-257. http://dx.doi.org/10.1207/s15327655jchn1904_05

Lazarus, R. S. (1991). Emotion and adaptation. New York: Oxford University Press.

Massi-Lindsey, L. L. (2005). Anticipated guilt as behavioral motivation: An examination of appeals to help unknown other through bone marrow donation. Human Communication Research, 31(4), 453-481. http://dx.doi.org/10.1111/j.1468-2958.2005.tb00879.x

Meyerowitz, B. E., \& Chaiken, S. (1987). The effect of message framing on breast self-examination attitudes, intentions, and behavior. Journal of Personality and Social Psychology, 52, 500-510.

http://dx.doi.org/10.1037//0022-3514.52.3.500

Miller, C. H., Burgoon, J. K., \& Hall, J. R. (2007). The effects of implicit theories of moral character on affective reactions to moral transgressions. Social Cognition, 25, 819-832. http://dx.doi.org/10.1521/soco.2007.25.6.819

Miller, C. H., Burgoon, M., Grandpre, J., \& Alvaro, E. (2006). Identifying principal risk factors for the initiation of adolescent smoking behaviors: The significance of psychological reactance. Health Communication, 19, 241-252. http://dx.doi.org/10.1207/s15327027hc1903_6

Miller, C. H., Lane, L. T., Deatrick, L. M., Young, A. M., \& Potts, K. A. (2007). Psychological reactance and promotional health messages: The effects of controlling language, lexical concreteness, and the restoration of freedom. Human Communication Research, 33, 219-240. http://dx.doi.org/10.1111/j.1468-2958.2007.00297.x

Mongeau, P. A. (1998). Another look at fear-arousing persuasive appeals. In M. Allen \& R. W. Priess (Eds.)., Persuasion: Advances through meta-analysis (p. 53-68). Cresskill, NJ: Hampton Press.

National Cancer Institute. (2008). Tobacco statistics snapshot. http://www.cancer.gov/cancertopics/tobacco/statisticssnapshot

Netemeyer, R. G., Andrews, J. C., \& Burton, S. (2005). Effects of antismoking advertising-based beliefs on adult smokers' consideration of quitting. American Journal of Public Health, 95, 1062-1066. http://dx.doi.org/10.2105/ajph.2004.050195

Patterson, F., Lerman, C., Kaufmann, V. G., Neuner, G. A., \& Audrian-McGovern, J. (2004). Cigarette smoking practices among American college students: Review and future directions. Journal of American College Health, 52, 203-211. http://dx.doi.org/10.3200/jach.52.5.203-212

Paul, R. H., Brickman, A. M., Cohen, R. A., Williams, L. M., Niaura, R., Pogun, S., Clark, R., Gunstad, J., \& Gordan, E. (2006). Cognitive status of young and older cigarette smokers: data from the international brain database. Journal of Clinical Neuroscience, 13, 457-465. http://dx.doi.org/10.1016/j.jocn.2005.04.012

Pechmann, C., \& Reibling, E. T. (2006). Antismoking advertisements for youths: An independent evaluation of health, counter-industry, and industry approaches. American Journal of Public Health, 96, 906-913.

http://dx.doi.org/10.2105/ajph.2004.057273.

Quick, B. L., Bates, B. R., \& Quinlan, M. R. (2009). The utility of anger in promoting clean indoor air policies. Health Communication, 24, 548-561. http://dx.doi.org/10.1080/10410230903104939. 
Rothman, A. J., Bartels, R. D., Wlaschin, J., \& Salovey, P. (2006). The strategic use of gain- and loss-framed messages to promote healthy behavior: how theory can inform practice. Journal of Communication, 56, 202-220. http://dx.doi.org/10.1111/j.1460-2466.2006.00290.x

Rothman, A. J., Salovey, P., Antone, C., Keough, K., \& Martin, C. D. (1993). The influence of message framing on intentions to perform health behaviors. Journal of Experimental Social Psychology, 29, 408-433. http://dx.doi.org/10.1006/jesp.1993.1019

Salovey, P., \& Williams-Piehota, P. (2004). Field experiments in social psychology: Message framing and the promotion of health protective behaviors. American Behavioral Scientist, 47, 488-505. http://dx.doi.org/10.1177/0002764203259293

Schneider, T. R., Salovey, P., Pallonen, U., Mundorf, N., Smith, N. F., \& Steward, W. T. (2001). Visual and auditory message framing effects on tobacco smoking. Journal of Applied Social Psychology, 31, 667-682. http://dx.doi.org/10.1111/j.1559-1816.2001.tb01407.x

Sepe, E., \& Glantz, S. A. (2002). Bar and club tobacco promotions in the alternative press: Targeting young adults. American Journal of Public Health, 93(1), 75-78. http://dx.doi.org/10.2105/ajph.92.1.75

Shen, L., \& Dillard, J. P. (2009). Message frames interact with motivational systems to determine depth of message processing. Health Communication, 24(6), 504-514. http://dx.doi.org/10.1080/10410230903104897

Southwell, B. G., \& Yzer, M. C. (2009). When and why interpersonal talk matters for campaigns. Communication Theory, 19, 1-8. http://dx.doi.org/10.1111/j.1468-2885.2008.01329.x

Stephenson, M. T., \& Witte, K. (2000). Creating fear in a risky world: Generating effective health risk messages. In R. E. Rice \& C. K. Atkin (Eds.), Public communication campaigns (pp. 88-104). Thousand Oaks, CA: Sage.

Substance Abuse and Mental Health Services Administration (2010). Results from the 2009 National Survey on Drug Use and Health: Volume I. Summary of National Findings (Office of Applied Studies, NSDUH Series H-38A, HHS Publication No. SMA 10-4586 Findings). Rockville, MD.

Tangney, J. P., Wagner, P. E., Hill-Barlow, D., Marschall, D. E., \& Gramzow, R. (1996). Relation of shame and guilt to constructive versus destructive responses to anger across the lifespan. Journal of Personality and Social Psychology, 70, 797-809. http://dx.doi.org/10.1037//0022-3514.70.4.797

Traeen, B., \& Kyalem, I. L. (2007). Investigating the relationship between past contraceptive behavior, self-efficacy, and anticipated shame and guilt in sexual contexts among Norwegian adolescents. Journal of Community \& Applied Social Psychology, 17, 19-34. http://dx.doi.org/10.1002/casp.869

U.S. Department of Health and Human Services, Centers for Disease Control and Prevention, National Center for Chronic Disease Prevention and Health Promotion, Office on Smoking and Health (2006). Best practices for comprehensive tobacco control programs. Atlanta, GA: U.S. Department of Health and Human Services.

Wakefield, M., Flay, B., Nichter, M., \& Giovino, G. A. (2003). Effects of anti-smoking advertising on youth smoking: A review. Journal of Health Communication, 8(3), 229-247. http://dx.doi.org/10.1080/10810730305686

Wetter, D. W., Kenford, S. L., Welsch, S. K., Smith, S. S., Fouladi, R. T., Fiore, M. C., \& Baker, T. B. (2004). Prevalence and predictors of transitions in smoking behavior among college students. Health Psychology, 23, 168-177. http://dx.doi.org/10.1037/0278-6133.23.2.168

Witte, K. (1992). Putting the fear back into fear appeals: The extended parallel process model. Communication Monographs, 59, 225-249. http://dx.doi.org/10.1080/03637759209376276

Witte, K. (1994). Fear control and danger control: A test of the extended parallel process model (EPPM). Communication Monographs, 61, 113-134. http://dx.doi.org/10.1080/03637759409376328

Witte, K., \& Allen, M. (2000). A meta-analysis of fear appeals: Implications for effective public health campaigns. Health Education \& Behavior, 27(5), 591-615.http://dx.doi.org/10.1177/109019810002700506

Wong, N. C. H., \& Cappella, J. N. (2009). Anti-smoking threat and efficacy appeals: Effects on smoking cessation intentions for smokers low and high in readiness to quit. Journal of Applied Communication Research, 37(1), 1-20.

\section{$(\mathrm{cc}) \mathrm{BY}$}

This work is licensed under a Creative Commons Attribution 3.0 License. 